Book Review

\title{
Wetland Ecology Principles and Conservation, Second Edition
}

\section{Richard Smardon}

Department of Environmental Studies, SUNY College of Environmental Science and Forestry, 1 Forestry Drive, Syracuse, NY 13210 USA; E-Mail: rsmardon@esf.edu; Tel.: +1-315-470-6576; Fax: +1-315-470-6915

Received: 28 January 2014; in revised form: 12 March 2014 / Accepted: 25 March 2014 /

Published: 2 April 2014

\begin{abstract}
This is a book review of Wetland Ecology Principles and Conservation, second edition, by Paul Keddy. This review focuses on the book's content as it relates to wetland sustainability for both science and management. Besides overall comments, comparisons are made with the first edition of the book and then very specific chapter-by-chapter relationships to wetland sustainability are made to illustrate specific applications toward wetland sustainability.
\end{abstract}

Keywords: book review; Paul Keddy; sustainability; wetland ecology and management

\section{Introduction and Book Organization}

This is a review of the second edition of this book and focuses specifically on its contribution to wetland sustainability science and management. The other focus of this review is to compare it to other wetland ecology and management texts, such as Mitsch and Gosselink's book "Wetlands". The structure of the book is similar to the first edition but now has 14 chapters as opposed to the original 12 , which was reviewed by Leopold in 2002 [1]. There is a slight reordering of the chapters as well as the addition of two chapters, but the structure is similar with early introductory chapters and building concepts related to wetland science ending in chapters more focused on wetland management.

The other similar wetland textbook is Wetlands By William Mitsch and James Gosselink [2], which has been through at least three editions. There are basic differences between these two wetland textbooks. Keddy's book integrates different wetland types throughout the discussion of different wetland processes; and utilizes international wetland examples throughout in nearly all the chapters. Mitch and Gosselink [2] spend much of their book addressing processes within different wetland types and have much more of a North American focus in regard to wetland management issues. 


\section{Relevance to Wetland Sustainability}

So back to sustainability - the reviewer would like to start with the back of the book in Chapter 14 on page 415 when Keddy quotes "A thing is right when it tends to preserve the integrity, sustainability and beauty of the biotic community" [3]. Keddy goes on to define conditions of integrity as monitoring biological diversity, ensuring ecosystem persistence through time and monitoring performance of ecological services [4] (p. 415). This sounds like a pretty good process of ensuring wetland sustainability, which comes close to the Ramsar definition of sustainability, which is hardly mentioned in this book. He mentions later in the same chapter that European managers tend to favor using monitoring historical human-influenced altered wetland landscapes, whereas North American managers tend to focus on creating wetland ecosystems that occurred before human influence. This reviewer thinks there is credence to these management views but since this book focuses on many international wetland management issues - this reviewer wondered why the Ramsar wetland classification (which includes manmade wetlands) and sustainable management principles include wise use of wetlands as "their sustainable utilization for the benefit of human kind in a way compatible with the maintenance of the natural properties of the ecosystem" [5] (p. 9) is not cited. This shows the author's bias toward preservation and possible restoration of wetland systems that are most susceptible to human impacts of hydrologic alteration and fertilization, which he admits.

Chapter 11 on Wetland Services and Functions is a good summary of the many "ecosystems services" provided by wetlands to humans and he also includes a section on wetland valuation on services and functions. The Millennium Ecosystem Assessment [6] Report "Ecosystems and Human Well-being; Wetlands and Water" of 2005 is hardly mentioned. This report outlines a very complete list of wetland ecosystem services (similar to Keddy's) as well as system of analyzing major drivers causing wetland change and degradation. This reviewer would like to have seen more integration and/or discussion of this very important international ecosystem assessment policy framework. There has been a bit more progress in wetland ecosystem service valuation to by International IUCN scholars [7] and well as the US Environmental Protection agency [8] that would have been good to refer to.

The other wetland management omission, which the author freely admits, is the human use and management framework of regulation, and management decision-making. Key sources, which could have been utilized a bit more is the Ramsar Convention Directorate and publications, the Millennium report previously mentioned, Marchand and De Hawes [9] report on the "The People's Role in Wetland Management" and the reviewer's own book [5], which looks at the role of government as well as nongovernment and community based organizations. The issue here is that we need to be concerned both with wetland within reserves as well as wetlands outside of reserves, and the respective roles of scientists, wetlands managers, government regulators and nongovernment organizations.

But within one book - there is only so much that you can cover. Within the following chapters this reviewer has noted specific contributions that the author has made that have direct linkages to wetland sustainability. In general, this reviewer appreciates the various international examples given with each chapter. 


\section{Chapter by Chapter Relevance to Wetland Sustainability}

In Chapter 2 on Flooding, Keddy utilized interesting examples to talk about the impact of reservoirs and dams on floodplain dynamics, artificially stabilizing flows, and increasing or decreasing flood flows. There is also the opportunity to reintroduce a similar hydrology as pointed out in case studies such as the Kafue flats in Zambia or the Tram Chim Wildlife Reserve within the Mekong Delta in Vietnam [5]. The issue here is that reintroducing and emulating the flooding hydro period could be a way of reducing impact.

Chapter 3 is good treatment of Fertility. Keddy uses the Florida Everglades as an example of nutrient enrichment and resultant impacts as well as Tampa Bay and Lake Okeechobee. He questions the utilization of treatment wetlands, but there have been very successful utilization of treatment wetland in Europe, Australia and North America - but this reviewer agrees that the scaling issue is key [10]. So there are large-scale issues of nutrient enrichment affecting fertility, but potential smaller scale use of utilizing water quality treatment wetlands to mediate such impacts.

In Chapter 4 on Disturbance he discusses tradition utilization of wetland resources by mowing, peat cutting and logging and the resultant impacts especially in the Mississippi Delta. There are a few examples of sustainable wetland harvesting such as the Mankote mangrove in St Lucia for charcoal production [5] but careful management is needed. So we could have certain sustainable renewable utilization of wetlands but not large-scale utilization that would cause ecological disturbance.

In Chapter 5 Competition - Keddy addresses the issue of vulnerable wetland habitats at the edge of wetland systems, which are most susceptible to human impacts. He also addresses the problem that certain types of wetlands are very hard to maintain and create given fertility, disturbance and competition interactions. This is a key point often overlooked in other references - that key impacts are incurred by wetlands at the edges of wetland systems.

In Chapter 6 Herbivory he notes both the traditional use of wetlands for mowing to feed livestock, roof thatching as well as invasive species overgrazing wetlands. This is especially relevant for developing country context where wetlands are being utilized for food and fiber or providing valuable ecological services for subsistence purposes [5].

In Chapter 7 on Burial - this is rarely covered in wetland texts and addresses the role of sediment load for floodplain and deltaic wetland systems. He also utilizes the Louisiana delta system to discuss the ecological effects of rising sea levels and change in GHG rates. Adequate sediment load is a critical issue for long-term wetland sustainability and can also be seen in the Axios river delta system in Greece [5] as well as other deltaic wetland systems around the world.

Chapter 9 includes Diversity of wetland dependent fish, water birds, amphibians and mammals. The author notes that our attempts to increase diversity by management can possibly reduce the species pool or have unintended results - which is a very salient point. The author emphasizes the inter play of different ecological processes affecting diversity.

In Chapter 10 on Zonation the author includes a discussion of climate induced sea level rise on low lying wetland areas, such as Louisiana and Bangladesh as well as North American shores, which lack low gradients. He also introduces the management options of adaption, planned retreat (relocate communities), accommodation and protection. This is a welcome addition to the discussion of zonation as climate change is just beginning to be discussed in other wetland ecology textbooks. 
In Chapter 12 is Research Paths Forward the author presents ways of wetland species accounting, as well as wetland delineation, inventory and evaluation as it is being done in Canada and the US plus the challenges of science and it relates to wetland restoration. The issue here, from an international context, is that many regions of the world do not have the advantage of such wetland research and wetland management techniques. Also many of these same wetlands are being heavily utilized for food and fiber-so what management techniques would be most appropriate?

Chapter 13 Restoration offers several examples of restoration such as the Everglades Protection Plan and the Danube River, restoration terms, as well as restoration principles. The author also introduces wetland manager responsibilities for monitoring, interpreting results and making adaptive changes. This reviewer would propose more emphasis on adaptive management as this has been utilized more by wetland managers to date.

Chapter 14 Conservation and Management was previously addressed but is fairly comprehensive and ends with a useful checklist for wetland managers. This reviewer would subdivide this section into wetland areas within preserves (where you can control management actions) and those wetlands outside wetland preserves that are privately owned. The issue here is that publically controlled wetlands in reserves may have different management methods versus privately owned wetlands.

\section{Summary}

One of the strengths of Keddy's book is that he carefully builds wetland ecology concepts from very basic processes to more complex relationships as the reader moves from chapter to chapter. This is especially true for wetland plant ecology. This approach differs somewhat from Mitsch and Gosselink's Wetland book [2] where they separate coastal from wetland systems into two sections of the book and do not go into such depth. The other strength of Keddy's book is that he incorporates international wetland management examples throughout each of the chapters, as well as well as the two final chapters on "restoration" and "conservation and management". This makes Keddy's book [4] a bit more international in scope whereas Mitch and Gosselink's book [2] has more of a North American focus.

At the end of the book, Keddy states that humans are "the problem" in terms of wetland degradation. But they can also be the solution if innovation ecosystem-based management is utilized with all parties playing key roles, as pointed out in both the Wadden Sea Management Plan in the Netherlands, Germany and Denmark and the Great Lakes Wetland Conservation Plan in Canada [5]. Sustainable wetland science is key to understanding wetland systems and the stresses on those systems, which this reviewer thinks Keddy's book [4] does an excellent job in presenting. He has his biases on conserving and protecting those nutrient restricted wetlands at the periphery, which are most susceptible to degradation or elimination, but freely admits this.

\section{Acknowledgments}

The author wishes to thank Donald Leopold for sharing his review of the first edition of this book.

\section{Conflicts of Interest}

The author declares no conflict of interest. 


\section{References}

1. Leopold, D. Books reviews: Wetland ecology principles and conservation. Nat. Areas J. 2002, 22, $166-167$.

2. Mitsch, W.J.; Gosselink, J.G. Wetlands, 3rd ed.; John Wiley and Sons: New York, NY, USA, 2000.

3. Leopold, A. A Sand County Almanac; Oxford University Press: New York, NY, USA, 1949.

4. Keddy, P.A. Wetland Ecology Principles and Conservation; Cambridge University Press: Cambridge, IK, USA, 2010; pp. 1-497.

5. Smardon, R.C. Sustaining the Worlds Wetlands; Setting Policies and Resolving Conflicts; Springer Press: New York, NY, USA, 2009.

6. Millennium Ecosystem Assessment, M.E.A. Ecosystems and Human Well Being: Wetlands and Water Synthesis; Water Resources Institute: Wash, DC, USA, 2005.

7. Emerton, L. Values and Rewards: Counting and Capturing Ecosystem Water Services for Sustainable Development; IUCN Water, Nature and Economics Technical paper No. 1; International Union for Conservation of Nature (IUCN): Cambridge, UK, 2005.

8. Ringold, P.L.; Boyd, J.; Landers, D.; Weber, M. What data should we collect? A framework for identifying indicators of ecosystems contributions to human well-being. Front. Ecol. Environ. 2013, 11, 98-105.

9. Marchand, M.; Udo de Haes, H.A. The peoples role in wetland management. Landsc. Urban Plan. 1991, 20, 1-276.

10. Kadlec, R.H.; Knight, R.L. Treatment Wetlands; CRC Lewis Publishers: Boca Raton, FL, USA, 1996.

(C) 2014 by the authors; licensee MDPI, Basel, Switzerland. This article is an open access article distributed under the terms and conditions of the Creative Commons Attribution license (http://creativecommons.org/licenses/by/3.0/). 